Ophthalmologe 2022 $\cdot 119: 109$

https://doi.org/10.1007/s00347-021-01560-9

(๑) The Author(s), under exclusive licence to Springer Medizin Verlag GmbH, ein Teil von Springer Nature 2022

\section{Frei flottierende uveale Zyste in der Vorderkammer}

\author{
Harald C. Gäckle
}

Augenlaserzentrum Neu-Ulm, Neu-Ulm, Deutschland

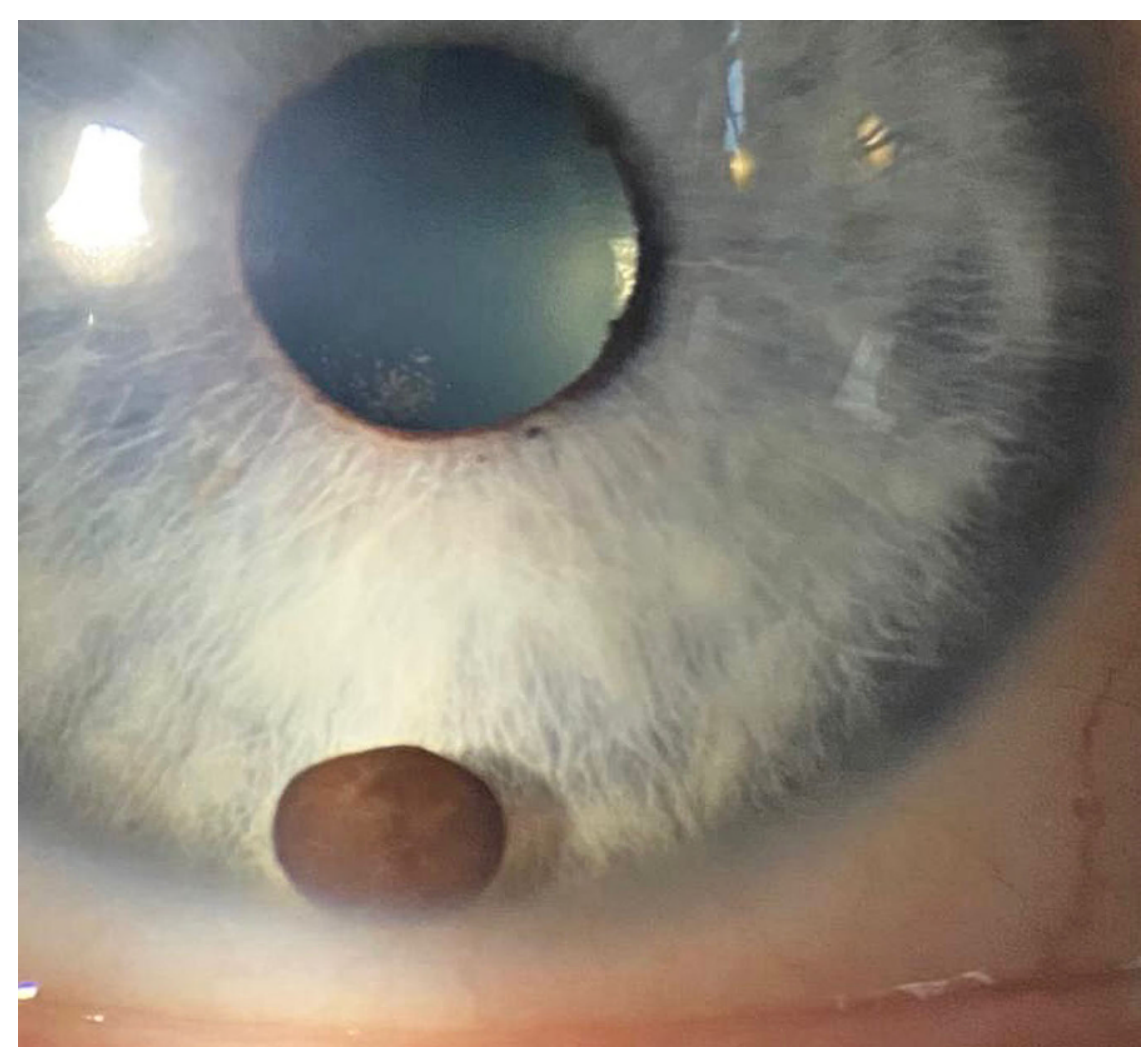

Abb. $1 \Delta$ Die frei flottierendeZyste führte zu einer signifikanten Endothelzahlminderung am betroffenen Auge und zu pigmentierten Endothelbeschlägen und wurde daraufhin operativ entfernt. Uveale Zysten entstehen als Abschnürungen der Iris oder des Ziliarkörpers (idiopathisch, nach Uveitis oder nach Trauma) und kommen im Tierreich (Hunde) relativ häufiger vor als beim Menschen

\section{Korrespondenzadresse}

\section{Dr. med. Harald C. Gäckle}

Augenlaserzentrum Neu-Ulm

Edisonallee 19, 89231 Neu-Ulm, Deutschland

drgaeckle@alz-neu-ulm.de 